\title{
Neoadjuvant Therapy in Differentiated Thyroid Cancer
}

\author{
Rajan P. Dang, ${ }^{1}$ Daniel McFarland, ${ }^{2}$ Valerie H. Le, ${ }^{1}$ Nadia Camille, ${ }^{2}$ Brett A. Miles, ${ }^{3}$ \\ Marita S. Teng, ${ }^{3}$ Eric M. Genden, ${ }^{3}$ and Krzysztof J. Misiukiewicz ${ }^{2}$ \\ ${ }^{1}$ Department of Medical Education, Icahn School of Medicine at Mount Sinai, New York, NY, USA \\ ${ }^{2}$ Department of Hematology-Oncology, Tisch Cancer Institute, Icahn School of Medicine at Mount Sinai, New York, NY, USA \\ ${ }^{3}$ Department of Otolaryngology-Head and Neck Surgery, Icahn School of Medicine at Mount Sinai, New York, NY, USA
}

Correspondence should be addressed to Rajan P. Dang; dangr@ent.wustl.edu

Received 20 December 2015; Revised 10 August 2016; Accepted 29 August 2016

Academic Editor: S. Curley

Copyright (C) 2016 Rajan P. Dang et al. This is an open access article distributed under the Creative Commons Attribution License, which permits unrestricted use, distribution, and reproduction in any medium, provided the original work is properly cited.

\begin{abstract}
Objectives. Invasion of differentiated thyroid cancer (DTC) into surrounding structures can lead to morbid procedures such as laryngectomy and tracheal resection. In these patients, there is a potential role for neoadjuvant therapy. Methods. We identified three studies involving the treatment of DTC with neoadjuvant chemotherapy: two from Slovenia and one from Japan. Results. These studies demonstrate that in selected situations, neoadjuvant chemotherapy can have a good response and allow for a more complete surgical resection, the treatment of DTC. Additionally, the SELECT trial shows that the targeted therapy lenvatinib is effective in the treatment of DTC and could be useful as neoadjuvant therapy for this disease due to its short time to response. Pazopanib has also demonstrated promise in phase II data. Conclusions. Thus, chemotherapy in the neoadjuvant setting could possibly be useful for managing advanced DTC. Additionally, some of the new tyrosine kinase inhibitors (TKIs) hold promise for use in the neoadjuvant setting in DTC.
\end{abstract}

\section{Introduction}

Neoadjuvant chemotherapy is integrated into the treatment of several cancers, including head and neck squamous cell carcinoma (hnSCC) [1]. In a phase III study by Licitra and Vermorken, rates of mandibular resection were significantly lower in hnSCC patients receiving neoadjuvant chemotherapy, thus demonstrating the ability of this treatment to preclude morbid and aggressive surgery [2]. On the other hand, neoadjuvant chemotherapy does not have an established role in differentiated thyroid cancer (DTC). Patients with thyroid cancer are historically treated with surgical resection of the primary tumor and locoregional nodal metastasis followed by radioiodine ablation (RAI).

While the majority of thyroid cancers present as locally resectable tumors with minimal surgical morbidity, occasionally the primary tumor has invaded critical structures, complicating the surgical treatment plan. Direct invasion of the larynx, trachea, pharynx, esophagus, recurrent laryngeal nerve, strap muscles, and/or carotid artery occurs in 7\%-16\% of patients with thyroid cancer [3]. Extensive invasion of the primary tumor into surrounding structures can necessitate relatively morbid procedures such as laryngectomy, tracheal resection, and esophageal-pharyngeal resection. Nevertheless, the importance of complete resection cannot be overstated as approximately $80 \%$ of patients who die of thyroid cancer have locoregional recurrence [4]. Certainly, a small number of patients also present with disease that may not be amenable to surgical resection, or in some cases the patient may refuse surgical resection due to the surgical morbidity. In these cases, a discussion regarding the role of neoadjuvant chemotherapy or radiotherapy is warranted. Unfortunately, neoadjuvant external beam radiation therapy (XRT) can lead to fibrosis, which can make resection of the thyroid more challenging for the surgeon. In these situations, there is a potential role for neoadjuvant chemotherapy and there are data that suggest that in selected patients, this strategy could prove to be beneficial for the treatment of extensively invasive DTC.

In this review, we will describe the potential role of neoadjuvant therapy in the treatment of DTC. Chemotherapy generally has a limited role in DTC as it is associated 
TABLE 1: Select studies of chemotherapy in metastatic differentiated thyroid cancer.

\begin{tabular}{|c|c|c|c|}
\hline Author and year & Sample size & Intervention & Response \\
\hline $\begin{array}{l}\text { Gottlieb et al., } \\
1972[5]\end{array}$ & 6 with DTC. & $\begin{array}{l}\text { Various single and combination } \\
\text { agents, including doxorubicin. }\end{array}$ & $33.3 \%$ PR. \\
\hline $\begin{array}{l}\text { Gottlieb and Hill, } \\
1974[6]\end{array}$ & 15 with DTC. & $\begin{array}{l}\text { Doxorubicin at } 45,60 \text {, or } 75 \mathrm{mg} / \mathrm{m}^{2} \\
\text { IV. }\end{array}$ & $33.3 \%$ PR. \\
\hline $\begin{array}{l}\text { Matuszczyk et al., } \\
2008 \text { [7] }\end{array}$ & 22 with DTC. & $\begin{array}{l}\text { Doxorubicin at } 15 \mathrm{mg} / \mathrm{m}^{2} \mathrm{IV} \text { weekly } \\
\text { or } 60 \mathrm{mg} / \mathrm{m}^{2} \mathrm{IV} \text { every } 3 \text { weeks. }\end{array}$ & $5 \%$ PR, $42 \%$ SD , 53\% PD.* \\
\hline $\begin{array}{l}\text { Williams et al., } \\
1986[8]\end{array}$ & $\begin{array}{l}22 \text { with advanced thyroid cancer of } \\
\text { all histological subtypes. }\end{array}$ & $\begin{array}{l}\text { Doxorubicin } 60 \mathrm{mg} / \mathrm{m}^{2} \text { plus } \\
\text { cisplatin } 60 \mathrm{mg} / \mathrm{m}^{2}\end{array}$ & $9.1 \% \mathrm{PR}$. \\
\hline $\begin{array}{l}\text { Shimaoka et al., } \\
1985 \text { [9] }\end{array}$ & 35 with DTC. & $\begin{array}{l}\text { Doxorubicin } 60 \mathrm{mg} / \mathrm{m}^{2} \text { with } \\
\text { cisplatin } 40 \mathrm{mg} / \mathrm{m}^{2} \text { or doxorubicin } \\
\text { alone. }\end{array}$ & $\begin{array}{l}16 \% \text { and } 31 \% \text { ORR for combination } \\
\text { and monotherapy, respectively. }\end{array}$ \\
\hline $\begin{array}{l}\text { Matuszczyk et al., } \\
2010[10]\end{array}$ & 7 with DTC. & $\begin{array}{l}\text { Paclitaxel } 90-100 \mathrm{mg} / \mathrm{m}^{2} \text { and } \\
\text { gemcitabine } 1000 \mathrm{mg} / \mathrm{m}^{2}\end{array}$ & No responses observed. \\
\hline
\end{tabular}

with minimal survival benefit when used as single modality therapy. In the neoadjuvant setting, however, the most important factor for therapy is tumor response. A favorable tumor response may offer the patient and surgeon significant improvement in the ability to provide an oncologic surgical resection. Given that data on neoadjuvant therapy in DTC is extremely limited, we will first discuss chemotherapy in its more established role in the metastatic setting in an effort to assess tumor response rates as they might pertain to neoadjuvant therapy. We will then describe the results of studies demonstrating the efficacy of neoadjuvant chemotherapy in DTC as well as the data for newer, targeted agents in an effort to identify the best possible options for neoadjuvant therapy in DTC.

\section{Review}

2.1. Chemotherapy in Metastatic DTC. Although a limited number of chemotherapies have been used effectively in the neoadjuvant setting, chemotherapy has not been shown to be particularly effective in the metastatic setting. The only FDA-approved chemotherapy for DTC is doxorubicin, which offers minimal benefit and is associated with toxicity for patients with metastatic DTC. Doxorubicin was initially introduced to clinical practice due to a study by Gottlieb et al., which described 6 case reports of patients with DTC treated with various chemotherapy agents given alone or in combination [5]. Two patients (33.3\%), both of whom were treated with doxorubicin, had a partial response (PR). These results led to a prospective clinical trial studying 15 patients with DTC treated with doxorubicin, in which a $33 \% \mathrm{PR}$ was observed [6]. See Table 1 for details [5-10]. However, multiple, larger, and better-designed trials over the past 30 years have demonstrated that doxorubicin may not be as effective as previously believed [31]. For example, Matuszczyk et al. conducted a retrospective study in which doxorubicin was given to patients with DTC, finding only a 5\% PR [7].
Given the limited efficacy of doxorubicin as monotherapy, other chemotherapy combinations have been evaluated in clinical trials, but also with disappointing results. Williams et al. described a study with 22 patients with advanced thyroid cancer of all histological subtypes treated with doxorubicin and cisplatin [8]. They observed a 9.1\% PR and the treatment was associated with considerable toxicity, including one treatment-related death. Another study by Shimaoka et al. described patients that were randomized to doxorubicin with cisplatin or doxorubicin alone [9]. Among a group of 35 patients with DTC, the overall response rate (ORR) for combination therapy (16\%) was inferior to that of monotherapy (31\%).

While these results for both doxorubicin monotherapy and combination chemotherapy are discouraging for the treatment of metastatic DTC this data should be interpreted with caution. Chemotherapy is typically reserved for RAIrefractory cases of DTC, and thus the biology involved in these cases may be different from that seen in the preoperative setting $[31,32]$.

The following studies, on the other hand, explore the efficacy of doxorubicin as well as various other agents given as neoadjuvant chemotherapy in DTC.

2.2. Neoadjuvant Chemotherapy in DTC. We identified three studies involving the treatment of DTC with neoadjuvant chemotherapy: two from Slovenia and one from Japan. Response rates for these three studies are summarized in Table 2 [11-13]. Rates of residual tumor after resection are summarized in Table $3[11,12,14]$.

One of the studies from Slovenia described a retrospective, nonrandomized study of 29 patients with T3 or T4 follicular or Hurthle cell thyroid cancers treated from 1979 to 2004 in which the tumor was considered inoperable [11]. Mean age was 60.83 years. Mean tumor diameter was $9.3 \mathrm{~cm}$ and extrathyroid growth was seen in $15 / 29$ patients $(51.7 \%)$. Regional metastases were present in 6 patients $(20.7 \%)$ and 
TABLE 2: Responses to neoadjuvant chemotherapy in differentiated thyroid cancer.

\begin{tabular}{|c|c|c|c|}
\hline $\begin{array}{l}\text { Author and } \\
\text { year }\end{array}$ & Sample size & Intervention & Response \\
\hline $\begin{array}{l}\text { Besic et al., } \\
2012[11]\end{array}$ & $\begin{array}{l}29 \text { with T3 or T4 follicular or } \\
\text { Hurthle cell thyroid cancer. }\end{array}$ & $\begin{array}{l}\text { Vinblastine, vinblastine with } \\
\text { doxorubicin, or other regimens. }\end{array}$ & RR 44.8\%. \\
\hline $\begin{array}{l}\text { Besic et al., } \\
2013 \text { [12] }\end{array}$ & $\begin{array}{l}16 \text { with T3 or T4 papillary thyroid } \\
\text { cancer. }\end{array}$ & $\begin{array}{l}\text { Vinblastine, vinblastine with } \\
\text { doxorubicin, or other regimens. }\end{array}$ & RR 40\%. \\
\hline $\begin{array}{l}\text { Ito et al., } 2012 \\
\text { [13] }\end{array}$ & $\begin{array}{l}2 \text { with papillary thyroid cancer with } \\
\text { a squamous cell carcinoma } \\
\text { component. }\end{array}$ & Paclitaxel $80 \mathrm{mg} / \mathrm{m}^{2}$. & $50 \%$ PR, 50\% SD. \\
\hline
\end{tabular}

Definitions: PR: partial response, RR: response rate, defined as decrease in tumor size by $>50 \%$, and SD: stable disease.

TABLE 3: Rates of residual tumor after resection in differentiated thyroid cancer.

\begin{tabular}{lllr}
\hline Author and year & Sample size & Neoadjuvant chemotherapy & R0, R1, R2 \\
\hline Besic et al., 2012 [11] & $\begin{array}{l}\text { 29 with T3 or T4 follicular or } \\
\text { Hurthle cell thyroid cancer. }\end{array}$ & $\begin{array}{l}\text { Vinblastine, vinblastine with } \\
\text { doxorubicin, or other regimens. }\end{array}$ & 51.7\%, 34.5\%, and 13.8\%. \\
Besic et al., 2013 [12] & $\begin{array}{l}\text { 16 with T3 or T4 papillary } \\
\text { thyroid cancer. }\end{array}$ & $\begin{array}{l}\text { Vinblastine, vinblastine with } \\
\text { doxorubicin, or other regimens. }\end{array}$ & $12.5 \%, 62.5 \%$, and 25\%. \\
Hartl et al., 2014 [14] & 46 with extensively invasive DTC. & None. & $49 \%, 51 \%$, and 0\%. \\
\hline
\end{tabular}

Definitions: DTC: differentiated thyroid cancer, R0: resection with no residual tumor, R1: resection with microscopic residual tumor, and R2: resection with macroscopic residual tumor.

* is considered inoperable prior to neoadjuvant treatment.

distant metastases in $12(41.4 \%)$. Chemotherapy consisted of vinblastine for 19 patients $(65.5 \%)$, vinblastine with doxorubicin for 5 patients $(17.2 \%)$, and other regimens for the remaining 5 patients (17.2\%). Four patients (13.8\%) were also treated with preoperative XRT. Surgery was performed when the tumor was reduced after chemotherapy and/or XRT and the surgeon judged the tumor resectable. The median interval between the beginning of chemotherapy and surgical procedure was 36 days (range: 4-173 days). Tumor size was decreased by $>50 \%$ in 13 patients $(44.8 \%)$. For patients with distant metastases, tumor size decreased by $>50 \%$ in only $17 \%$ of patients, while in patients without distant metastases, tumor size decreased by $>50 \%$ in $65 \%$ of patients. Histopathology revealed wide areas of tumor necrosis in 7 patients (24\%). Tumor resection after chemotherapy was performed in all patients, resulting in R0 (defined as with no residual tumor), R1 (microscopic residual tumor), and R2 (macroscopic residual tumor) resections in 15 (51.7\%), 10 $(34.5 \%)$, and $4(13.8 \%)$ cases, respectively. Total thyroidectomy was performed in 24 patients $(82.6 \%)$ and lobectomy was performed in 5 patients $(17.2 \%)$. Toxicity data was not reported.

Similarly, the same group in Slovenia described a retrospective, nonrandomized study of 16 patients with T3 or T4 papillary thyroid cancer treated from 1988 to 2005 in which the tumor was considered to be inoperable [12]. Mean age was 63.06 years. Mean tumor diameter was $9.7 \mathrm{~cm}$ and extrathyroid growth was present in 13 patients $(81.3 \%)$. Regional metastases were present in 10 patients $(62.5 \%)$ and distant metastases in 7 (43.8\%). Chemotherapy consisted of vinblastine in 11 cases $(68.8 \%)$, vinblastine with doxorubicin in 2 cases $(12.5 \%)$, and other regimens in 3 cases $(18.8 \%)$.
Four patients were treated with preoperative XRT (25\%). Surgery was performed when the tumor was reduced after chemotherapy and/or XRT and the surgeon judged the tumor resectable. The median interval between the beginning of chemotherapy and surgical procedure was 28 days (range: 7161 days). After chemotherapy, tumor size decreased by $>50 \%$ in 7 patients (44\%). R0, R1, and R2 resection was performed in $2(12.5 \%), 10(62.5 \%)$, and $4(25 \%)$ cases, respectively. Total thyroidectomy was performed in 11 patients $(68.8 \%)$ and lobectomy in 5 patients (31.3\%). No toxicity was reported. Interestingly, these two studies from Slovenia describe very different rates of residual tumor after resection (see Table 3). Given that response rates were similar between the first and second study, average tumor size was similar, and the surgeries were performed at the same institution over a similar period of time; this difference is difficult to account for. It is likely due to a higher rate of extrathyroid growth in the second study (81.3\%) when compared to that of the first study $(51.7 \%)$. Given this difference in extrathyroid growth and resections between the two groups, it is possible that papillary thyroid carcinoma can be more invasive and consequently more difficult for the surgeon to resect completely. These results are also difficult to characterize given the variety of chemotherapy strategies utilized and the time period over which the reviews were performed.

An additional study from Japan evaluated the effect of weekly paclitaxel chemotherapy in 3 patients with papillary thyroid cancer with a squamous cell carcinoma component (a very aggressive tumor with behavior resembling anaplastic thyroid cancer) [13]. Weekly chemotherapy was performed as induction for 2 of the patients, and all patients underwent locally curative surgery with weekly adjuvant chemotherapy 
after surgery. The response to chemotherapy was evaluated based on RECIST 1.1 criteria. The first patient was a 70-yearold woman with a solitary $5.9 \mathrm{~cm}$ thyroid tumor and multiple node metastases. She additionally had an incomplete right laryngeal nerve paralysis, likely due to tumor invasion. CT scan revealed multiple lung metastases. She received weekly induction paclitaxel at $80 \mathrm{mg} / \mathrm{m}^{2}$ for 3 cycles. The tumor size decreased by $45 \%$, and lung metastases disappeared after induction. The patient underwent total thyroidectomy with modified radical neck dissection, and the tumor was completely resected. Lung metastases were identified again 6 months after surgery. The patient received 13 cycles of weekly paclitaxel, but the metastases enlarged gradually. The patient died 21 months after diagnosis and 18 months after surgery. The second patient was a 68 -year-old woman with a $4.4 \mathrm{~cm}$ thyroid tumor and a single cervical node metastasis, without distant metastases. The patient received induction therapy with weekly paclitaxel (again at $80 \mathrm{mg} / \mathrm{m}^{2}$ ) for 2 cycles. The tumor size decreased by $15 \%$; this result was evaluated as stable disease (SD). The patient underwent total thyroidectomy and modified neck dissection, and the tumor was completely resected. At the time of publication of this study, the patient was alive 29 months after her diagnosis and 27 months after surgery with no evidence of recurrence. No toxicity was reported for either patient receiving induction therapy.

The results from these studies indicate that neoadjuvant chemotherapy may have some effectiveness in DTC and should be considered in select cases. Neoadjuvant regimens consisted mostly of vinblastine, doxorubicin, and/or paclitaxel and offered superior responses compared to doxorubicin alone (or with cisplatin). Of note, patients in these studies were typically older, with mean ages over 60 . Thus, neoadjuvant chemotherapy can be both effective and tolerable in this population.

Despite these results, the data is limited to these two retrospective studies and two patients from a case series. Interestingly, none of these studies reported toxicity associated with neoadjuvant chemotherapy. While it is possible that neoadjuvant chemotherapy was well tolerated by the patients in these studies, the lack of concrete toxicity data is a significant weakness. Ideally, recommendations for treatment using neoadjuvant therapy would be based on randomized controlled trials (RCTs); however it is unlikely that enough patients could be accrued to power such a study. Consequently, there is a need for more retrospective studies and case reports in order to enhance the current data for this treatment.

2.3. Targeted Agents. The studies described thus far in this review have all used cytotoxic chemotherapy, which is relatively indiscriminate in its toxicity. In contrast, newer targeted therapies are based on specific genetic properties of tumors and are generally less toxic as a result. In particular, tyrosine kinase inhibitors (TKIs) have shown promise in the treatment of DTC. In 2013, sorafenib was approved for the treatment of metastatic DTC. Furthermore, lenvatinib was found to extend progression-free survival (PFS) in RAI-resistant DTC in the phase III SELECT trial and was approved for the treatment of metastatic DTC in 2015. Although there are no adjuvant data for these drugs, the phase III trial data is thought provoking for the potential role of targeted therapy in the neoadjuvant setting.

The double-blind, randomized, multicenter, phase III DECISION trial examined sorafenib efficacy and safety versus placebo in patients with progressive RAI-refractory DTC [15]. A total of 417 patients were randomized; 207 were to sorafenib and 210 to placebo. Ninety-six percent of patients had metastatic disease. ORR in the sorafenib versus placebo arms was $12.2 \%$ and $0.5 \%$ (all responses were partial responses). Stable disease $\geq 6$ months was achieved in $42 \%$ versus $33 \%$ for sorafenib versus placebo, respectively. The most common any-grade treatment-emergent adverse events in the sorafenib arm were hand-foot skin reaction, diarrhea, alopecia, rash/desquamation, fatigue, weight loss, and hypertension. Tolerability in this study was consistent with the known sorafenib safety profile. Consequently, this study demonstrated a significant advantage of sorafenib over placebo with limited toxicity. However, the $12.2 \%$ ORR is still very low and is not ideal for neoadjuvant therapy. This result is consistent with other phase II data regarding sorafenib [33]. See Table 4 for a summary of studies describing targeted therapy in DTC [15-26].

The multicenter, randomized, placebo-controlled, phase III SELECT trial presented at the American Society of Clinical Oncology (ASCO) 2014 annual meeting examined the efficacy and safety of lenvatinib versus placebo in patients with RAI-refractory DTC [24]. Patients were allowed to have received $\leq 1$ prior vascular endothelial growth factor receptor(VEGFR-) targeted therapy. A total of 392 patients were randomized in a 2:1 ratio to lenvatinib or placebo. Complete response (CR) rates were $1.5 \%$ for lenvatinib and $0 \%$ for placebo, and PR rates were $63.2 \%$ for lenvatinib and $1.5 \%$ for placebo. Median time to response was 2.0 months. The most common lenvatinib treatment-related adverse events were hypertension (68\%), diarrhea (59\%), decreased appetite (50\%), weight loss (46\%), and nausea (41\%). Lenvatinibrelated grade $\geq 3$ adverse events were hypertension (42\%), proteinuria $(10 \%)$, weight loss $(10 \%)$, diarrhea $(8 \%)$, and decreased appetite $(5 \%)$. The dose was reduced in $78.5 \%$ of patients and discontinued due to adverse events in $14.2 \%$ of patients. Consequently, response rates for lenvatinib were far superior to those of sorafenib. Additionally, these results show that lenvatinib is a good candidate for use as neoadjuvant therapy in DTC, given its short time to response and a high response rate.

A phase II trial conducted by Bible et al. describes pazopanib as a promising new targeted agent for DTC [26]. Thirty-seven patients with metastatic, rapidly progressive, RAI-refractory DTC received pazopanib until disease progression and/or drug intolerance. Up to two previous therapies were allowed. Confirmed partial responses were seen in 18 patients (49\%). Sixteen patients $(43 \%)$ required dose reductions due to adverse events, the most common (of any grade) being fatigue (78.4\%), skin and hair hypopigmentation $(75.7 \%)$, diarrhea $(73 \%)$, and nausea $(73 \%)$. Two patients died during treatment, though they each had preexisting contributory disorders. 
TABLE 4: Summary of studies of targeted therapy in differentiated thyroid cancer.

\begin{tabular}{|c|c|c|c|}
\hline Author and year & Sample size & Intervention & Response \\
\hline $\begin{array}{l}\text { Brose et al., } 2014 \text { [15] } \\
\text { Phase III } \\
\text { DECISION trial }\end{array}$ & 417 with RAI-refractory DTC. & Sorafenib 400 mg 2x daily. & $\begin{array}{l}\text { ORR } 12.2 \% \text { and } 0.5 \% \text {, SD } 42 \% \text { and } \\
33 \% \text {. }\end{array}$ \\
\hline $\begin{array}{l}\text { Marotta et al., } 2013 \\
{[16]}\end{array}$ & 17 with RAI-refractory DTC. & Sorafenib 400 mg 2x daily. & $30 \% \mathrm{PR}, 41 \% \mathrm{SD}$ \\
\hline $\begin{array}{l}\text { de la Fouchardiere et } \\
\text { al., } 2013 \text { [17] }\end{array}$ & 45 with RAI-refractory DTC. & Sorafenib. & $29 \%$ PR. \\
\hline Chen et al., 2011 [18] & 9 with RAI-refractory DTC. & Sorafenib 200 mg 2x daily. & $33 \%$ PR, 44\% SD. \\
\hline $\begin{array}{l}\text { Cabanillas et al., } \\
2010[19]\end{array}$ & 13 with RAI-refractory DTC. & Sorafenib $400 \mathrm{mg}$. & $20 \%$ PR, $60 \%$ SD, $20 \%$ PD. \\
\hline $\begin{array}{l}\text { Sherman et al., } 2013 \\
{[20]}\end{array}$ & 19 with DTC. & $\begin{array}{l}\text { Sorafenib } 400 \mathrm{mg} 2 \mathrm{x} \text { daily and } \\
\text { everolimus } 5 \mathrm{mg} \text { daily. }\end{array}$ & $\begin{array}{l}\text { Papillary, 50\% PR and 38\% SD. } \\
\text { Hurthle cell, } 67 \% \text { PR and 33\% SD. } \\
\text { Follicular, 50\% PR and 50\% SD. }\end{array}$ \\
\hline $\begin{array}{l}\text { Sherman et al., } 2012 \\
\text { [21] }\end{array}$ & $\begin{array}{l}27 \text { with recurrent/refractory DTC, } 6 \\
\text { of whom with prior sorafenib. }\end{array}$ & $\begin{array}{l}\text { Sorafenib } 200 \mathrm{mg} 2 \mathrm{x} \text { daily with } \\
\text { temsirolimus } 25 \mathrm{mg} \text { weekly. }\end{array}$ & $38 \%$ PR if no prior sorafenib. \\
\hline Hong et al., 2011 [22] & 16 with metastatic DTC. & $\begin{array}{l}\text { Sorafenib } 400 \text { mg daily with } \\
\text { tipifarnib } 100 \mathrm{mg} 2 \mathrm{x} \text { daily. }\end{array}$ & $4.5 \% \mathrm{PR}$ and $36 \% \mathrm{SD}$. \\
\hline $\begin{array}{l}\text { Cabanillas et al., } \\
2010[23]\end{array}$ & 22 with metastatic DTC. & $\begin{array}{l}\text { Sorafenib with tipifarnib, dose } \\
\text { escalation trial. }\end{array}$ & 7\% PR, 86\% SD, 7\% PD. \\
\hline $\begin{array}{l}\text { Schlumberger, } 2014 \\
\text { [24] } \\
\text { Phase III SELECT } \\
\text { trial }\end{array}$ & 392 with RAI-refractory DTC. & Lenvatinib 24 mg daily. & $\begin{array}{l}\text { CR } 1.5 \% \text { and } 0 \% . \text { PR } 63.2 \% \text { and } \\
1.5 \% \text {. }\end{array}$ \\
\hline $\begin{array}{l}\text { Sherman et al., } 2011 \\
\text { [25] }\end{array}$ & 58 with RAI-refractory DTC. & Lenvatinib 24 mg daily. & PR 50\%. \\
\hline Bible et al., 2010 [26] & 37 with RAI-refractory DTC. & Pazopanib $800 \mathrm{mg}$ daily. & $49 \% \mathrm{PR}$. \\
\hline
\end{tabular}

Definitions: CR: complete response, DTC: differentiated thyroid cancer, ORR: overall response rate, PD: progressive disease, PR partial response, RAI: radioactive iodine, and SD: stable disease.

These data demonstrate that lenvatinib and pazopanib are promising agents for neoadjuvant therapy in DTC. The former has a documented short time to response, and both had good response rates with low toxicity. Furthermore, given that these drugs would be given for a short time period if administered as neoadjuvant therapy, long-term toxicity would also be minimal. However, there exists the theoretical concern of selecting for tumor cell clonality resistant to these new therapies if they are used early in the course of treatment as neoadjuvant therapy. If such a patient were to develop RAIresistant metastases, the treatment options for the patient would indeed be poor. However, this scenario is very unlikely, and its possibility should not preclude the consideration of targeted agents as neoadjuvant therapy in patients that could benefit from this treatment.

Sorafenib, on the other hand, had a relatively low response rate of $12 \%$ in a phase III trial, which is consistent with data from prior phase II trials. The different biochemical properties of these drugs may contribute to the considerable differences in response rates between sorafenib and lenvatinib/pazopanib (see Table 5 [27-30] for a summary of the molecular targets of these TKIs). Additional studies could be helpful in elucidating these differences. While ineffective on its own, there is the possibility that sorafenib could be effective in conjunction with other targeted therapies or cytotoxic chemotherapies. Further studies could elaborate on
TABLE 5: Molecular targets of the TKIs sorafenib, lenvatinib, and pazopanib.

\begin{tabular}{ll}
\hline Drug & Targets \\
\hline Sorafenib & Raf kinase, VEGFR1-3, PDGFR $\beta$, RET [27]. \\
Lenvatinib & VEGFR1-3, FGFR1-4, RET, c-Kit, PDGFR $\beta$ [28]. \\
Pazopanib & VEGFRs, PDGFR, c-Kit [29, 30]. \\
\hline
\end{tabular}

Definitions: FGFR: fibroblast growth factor receptor, PDGFR: platelet derived growth factor receptor, TKI: tyrosine kinase inhibitor, and VEGFR: vascular endothelial growth factor receptor.

the potential of combining different targeted therapies with each other or with cytotoxic chemotherapy.

\section{Discussion}

Neoadjuvant chemotherapy can preclude the need for aggressive and morbid surgery, such as laryngectomy, tracheal resection, or pharyngoesophageal resection [3]. It can also render an inoperable tumor operable and can improve a patient's prognosis by allowing a more complete resection of a patient's tumor. Furthermore, it can act on metastatic disease if present and add additional value to postoperative RAI, which is generally more efficacious for patients with only remaining microscopic disease rather than macroscopic. 
The current literature describes $\mathrm{R} 0$ and $\mathrm{R} 1$ resections as offering improved survival when compared to $\mathrm{R} 2$ resection [34-40]. However, the respective effects of R0 and R1 resections on prognosis are more controversial. The clinical benefits of complete resection are apparent in a retrospective single-center study by Hartl et al., in which they described 46 patients with DTC invading the trachea, larynx, pharynx, or esophagus, none of whom received neoadjuvant chemotherapy [14]. R0, R1, and R2 surgeries were performed in 22 (49\%), 24 (51\%), and 0 (0\%) patients, respectively. All patients received postoperative RAI, and $23(50 \%)$ received adjuvant XRT. The 10 -year local control rate was $100 \%$ for R0 patients and $75 \%$ for R1 patients; 5-year disease-specific survival was $95 \%$ for R0 patients and $84 \%$ for R1 patients.

Of note, the study by Hartl et al. seems to describe a more favorable R0/R1/R2 than the two Slovenian studies, despite the lack of neoadjuvant therapy in the former study. However, the tumors described in the Slovenian studies were considered inoperable at the start and consequently were likely larger and more extensive from the beginning than those described in the study by Hartl et al. Also of note, the studies from Slovenia seem to demonstrate that neoadjuvant therapy is more effective in patients without metastases. This is potentially due to the less aggressive biology of tumors that have not yet metastasized.

Neoadjuvant therapy could also be useful in certain specialized cases, for instance, those involving deep tracheal invasion or PET-positivity. For instance, some studies demonstrate that tracheal shaving is an effective procedure for the treatment of tracheal invasion when compared to sleeve resection (a more aggressive but more definitive procedure) [41, 42]. However, in cases of deep invasion, tracheal shaving has a greater risk of leaving gross disease behind [11]. Thus, neoadjuvant therapy could potentially reduce the extent of invasion and reduce the risk of residual disease after surgical resection. Likewise, neoadjuvant therapy may be useful in PET-positive DTC tumors. Prior studies have demonstrated that PET-positive tumors are often aggressive and RAI-resistant $[43,44]$. In these situations, neoadjuvant therapy might be a valuable tool in a setting in which treatment options are limited.

While VEGF is critical for tumor angiogenesis and growth, it is also imperative to wound healing [45]. Thus, a significant possible drawback of the use of anti-VEGF TKIs, such as sorafenib, lenvatinib, or pazopanib, as neoadjuvant therapy is the possibility of impaired wound healing after surgery. Consequently, the use of these agents as neoadjuvant therapy would potentially require a waiting period between drug administration and surgery, possibly allowing the tumor time to regrow. That being said, the current literature contains few reports of impaired healing or wound dehiscence following therapy with anti-VEGF TKIs. For instance, in the Phase III SELECT trial of lenvatinib, 6 of 118 deaths were determined to be treatment-related, and none of these were related to surgical or wound problems [46]. Of note, the package insert for lenvatinib reports a $0.8 \%$ rate of impaired healing and $0.4 \%$ of wound dehiscence [47]. Antiangiogenic therapy could also potentially lead to fistula formation in these patients given the potential for radiation and/or surgery around the trachea and esophagus. Tracheoesophageal fistula has been reported in lung cancer patients after treatment with the VEGF inhibitor bevacizumab in addition to radiation [48-50]. In another study, 5 of 43 head and neck cancer patients treated with bevacizumab and chemoradiotherapy developed an aerodigestive fistula [51]. However, a 2014 literature review conducted by Blevins et al. only yielded one case of antiangiogenic therapy for thyroid cancer resulting in aerodigestive fistula, though details regarding the patient's history were not published [52]. In the same paper, Blevins et al. report two cases of aerodigestive fistula in patients with DTC treated with antiangiogenic TKIs [52]. Both of these patients were previously treated with surgery and radiation. Thus, these data demonstrate a rare risk of fistula formation in patients with DTC treated with antiangiogenic TKIs.

Given that there is no data regarding the use of antiangiogenic TKIs as neoadjuvant therapy in DTC, it is difficult to speculate as to the possibility of postoperative wound dehiscence or fistula formation. Furthermore, there are no current guidelines for these drugs on how long to wait before surgery. While we believe that, in specific circumstances, neoadjuvant therapy might be a valuable tool in the treatment of DTC, these risks should be deliberated in any treatment plan. The possibility of a waiting period between drug administration and surgery should be considered while considering the risk of tumor regrowth. Given the lack of guidelines or data, these decisions should be made on the basis of the individual patient and tumor. More data need to be collected regarding the possibility of impaired wound healing or fistula formation after treatment with antiangiogenic TKIs in DTC before any recommendations on a waiting period between drug administration and surgery are made. In the opinion of the authors of this paper, an antiangiogenic TKI could be administered for approximately four months (with response first assessed after two months), and surgery could take place 4-6 weeks after stopping the drug. Again, however, additional data is necessary before establishing any guidelines for duration of therapy and the waiting period.

\section{Conclusions and Future Directions}

Currently, the role for neoadjuvant chemotherapy in DTC is not well established. However, our review shows that in selected situations neoadjuvant chemotherapy can be beneficial in the treatment of DTC. Moreover, the SELECT trial shows that the targeted therapy lenvatinib is effective and safe in the treatment of DTC and could potentially be useful as neoadjuvant therapy for this disease given its high response rate and short time to effect. Pazopanib has also demonstrated promise in phase II data, and sorafenib, while relatively ineffective alone, could possibly be useful in conjunction with other therapies.

There are still many unanswered questions regarding neoadjuvant therapy in DTC. There is still limited data on the respective effects of $\mathrm{R} 0, \mathrm{R} 1$, and $\mathrm{R} 2$ on prognosis. There are also no clear indications for the use of neoadjuvant therapy in DTC, and this decision would likely be made by the surgeon based on the extent of disease and complexity of 
the operation for the surgeon. It is unlikely that a sufficiently powered RCT will be conducted for this treatment, and, consequently, treatment recommendations will have to rely on strong retrospective data and case reports and series. Collaboration and cooperative research groups could possibly yield stronger data. Future studies should potentially include combinations of targeted therapies with each other or other cytotoxic chemotherapies to further elucidate the possibilities for neoadjuvant therapy in DTC.

\section{Competing Interests}

Dr. Brett Miles has received funding within the past 2 years from Advaxis Pharmaceuticals for the investigatorinitiated study "Window of Opportunity Trial of Neoadjuvant ADXS 11-001 Vaccination Prior to Robot-Assisted Resection of HPV-Positive Oropharyngeal Squamous Cell Carcinoma." Otherwise, there are no competing interests to report.

\section{References}

[1] M. R. Posner, "Paradigm shift in the treatment of head and neck cancer: the role of neoadjuvant chemotherapy," The Oncologist, vol. 10, supplement 3, pp. 11-19, 2005.

[2] L. Licitra and J. B. Vermorken, "Is there still a role for neoadjuvant chemotherapy in head and neck cancer?" Annals of Oncology, vol. 15, no. 1, pp. 7-11, 2004.

[3] N. Ark, S. Zemo, D. Nolen, F. C. Holsinger, and R. S. Weber, "Management of locally invasive well-differentiated thyroid cancer," Surgical Oncology Clinics of North America, vol. 17, no. 1, pp. 145-155, 2008.

[4] S. G. Silverberg, R. V. Hutter, and F. W. Foote Jr., "Fatal carcinoma of the thyroid: histology, metastases, and causes of death," Cancer, vol. 25, no. 4, pp. 792-802, 1970.

[5] J. A. Gottlieb, C. S. Hill Jr., M. L. Ibanez, and R. L. Clark, "Chemotherapy of thyroid cancer. An evaluation of experience with 37 patients," Cancer, vol. 30, no. 3, pp. 848-853, 1972.

[6] J. A. Gottlieb and C. S. Hill Jr., "Chemotherapy of thyroid cancer with adriamycin. Experience with 30 patients," The New England Journal of Medicine, vol. 290, no. 4, pp. 193-197, 1974.

[7] A. Matuszczyk, S. Petersenn, A. Bockisch et al., "Chemotherapy with doxorubicin in progressive medullary and thyroid carcinoma of the follicular epithelium," Hormone and Metabolic Research, vol. 40, no. 3, pp. 210-213, 2008.

[8] S. D. Williams, R. Birch, and L. H. Einhorn, "Phase II evaluation of doxorubicin plus cisplatin in advanced thyroid cancer: a Southeastern Cancer Study Group Trial," Cancer Treatment Reports, vol. 70, no. 3, pp. 405-407, 1986.

[9] K. Shimaoka, D. A. Schoenfeld, W. D. DeWys, R. H. Creech, and R. DeConti, "A randomized trial of doxorubicin versus doxorubicin plus cisplatin in patients with advanced thyroid carcinoma," Cancer, vol. 56, no. 9, pp. 2155-2160, 1985.

[10] A. Matuszczyk, S. Petersenn, W. Voigt et al., "Chemotherapy with paclitaxel and gemcitabine in progressive medullary and thyroid carcinoma of the follicular epithelium," Hormone and Metabolic Research, vol. 42, no. 1, pp. 61-64, 2010.

[11] N. Besic, M. Auersperg, B. Gazic, M. Dremelj, and I. Zagar, "Neoadjuvant chemotherapy in 29 patients with locally advanced follicular or hürthle cell thyroid carcinoma: a phase 2 study," Thyroid, vol. 22, no. 2, pp. 131-137, 2012.
[12] N. Besic, M. Auersperg, M. Dremelj, B. Vidergar-Kralj, and B. Gazic, "Neoadjuvant chemotherapy in 16 patients with locally advanced papillary thyroid carcinoma," Thyroid, vol. 23, no. 2, pp. 178-184, 2013.

[13] Y. Ito, T. Higashiyama, M. Hirokawa et al., "Clinical trial of weekly paclitaxel chemotherapy for papillary thyroid carcinoma with squamous cell carcinoma component," Endocrine Journal, vol. 59, no. 9, pp. 839-844, 2012.

[14] D. M. Hartl, S. Zago, S. Leboulleux et al., "Resection margins and prognosis in locally invasive thyroid cancer," Head and Neck, vol. 36, no. 7, pp. 1034-1038, 2014.

[15] M. S. Brose, C. M. Nutting, B. Jarzab et al., "Sorafenib in radioactive iodine-refractory, locally advanced or metastatic differentiated thyroid cancer: a randomised, double-blind, phase 3 trial," The Lancet, vol. 384, no. 9940, pp. 319-328, 2014.

[16] V. Marotta, V. Ramundo, L. Camera et al., "Sorafenib in advanced iodine-refractory differentiated thyroid cancer: efficacy, safety and exploratory analysis of role of serum thyroglobulin and FDG-PET,' Clinical Endocrinology, vol. 78, no. 5, pp. 760-767, 2013.

[17] C. de la Fouchardiere, M.-H. Massicotte, I. Borget et al., "Sequential TKI treatments for iodine-refractory differentiated thyroid carcinomas," Journal of Clinical Oncology, vol. 31, supplement 15, abstract S6092, 2013.

[18] L. Chen, Y. Shen, Q. Luo, Y. Yu, H. Lu, and R. Zhu, "Response to sorafenib at a low dose in patients with radioiodine-refractory pulmonary metastases from papillary thyroid carcinoma," Thyroid, vol. 21, no. 2, pp. 119-124, 2011.

[19] M. E. Cabanillas, S. G. Waguespack, Y. Bronstein et al., "Treatment with tyrosine kinase inhibitors for patients with differentiated thyroid cancer: the M. D. Anderson experience," Journal of Clinical Endocrinology and Metabolism, vol. 95, no. 6, pp. 2588-2595, 2010.

[20] E. J. Sherman, A. L. Ho, M. G. Fury et al., "Phase II study of everolimus and sorafenib for the treatment of metastatic thyroid cancer," Journal of Clinical Oncology, vol. 31, supplement 1, abstract 6024, 2013.

[21] E. Sherman, A. Ho, M. Fury et al., "A phase II study of temsirolimus/sorafenib in patients with radioactive iodine (RAI)refractory thyroid carcinoma," Journal of Clinical Oncology, vol. 29, supplement, p. A5514, 2012.

[22] D. S. Hong, M. E. Cabanillas, J. Wheler et al., "Inhibition of the ras/raf/MEK/ERK and RET kinase pathways with the combination of the multikinase inhibitor sorafenib and the farnesyltransferase inhibitor tipifarnib in medullary and differentiated thyroid malignancies," The Journal of Clinical Endocrinology \& Metabolism, vol. 96, no. 4, pp. 997-1005, 2011.

[23] M. E. Cabanillas, R. Kurzrock, S. Sherman et al., "Phase I trial of combination sorafenib and tipifarnib: the experience of advanced differentiated thyroid cancer (DTC) and medullary thyroid cancer (MTC) (abstract 5586)," Journal of Clinical Oncology, vol. 28, supplement 15, p. S5586, 2010.

[24] "A phase 3, multicenter, double-blind, placebo-controlled trial of lenvatinib (E7080) in patients with 131I-refractory differentiated thyroid cancer (SELECT)," in Proceedings of the ASCO Annual Meeting, M. Schlumberger, Ed., Chicago, Ill, USA, 2014.

[25] S. Sherman, B. Jarzab, M. Cabanillas et al., "A phase II trial of the multitargeted kinase inhibitor E7080 in advanced radioiodine (RAI)-refractory differentiated thyroid cancer (DTC)," Journal of Clinical Oncology, vol. 29, no. 15, supplement, abstract 5503, 2011, Proceedings of the ASCO Annual Meeting. 
[26] K. C. Bible, V. J. Suman, J. R. Molina et al., "Efficacy of pazopanib in progressive, radioiodine-refractory, metastatic differentiated thyroid cancers: results of a phase 2 consortium study," The Lancet Oncology, vol. 11, no. 10, pp. 962-972, 2010.

[27] Y. E. Nikiforov and M. N. Nikiforova, "Molecular genetics and diagnosis of thyroid cancer," Nature Reviews Endocrinology, vol. 7, no. 10, pp. 569-580, 2011.

[28] E. Grande, J. J. Díez, C. Zafon, and J. Capdevila, “Thyroid cancer: molecular aspects and new therapeutic strategies," Journal of Thyroid Research, vol. 2012, Article ID 847108, 10 pages, 2012.

[29] R. Kumar, V. B. Knick, S. K. Rudolph et al., "Pharmacokineticpharmacodynamic correlation from mouse to human with pazopanib, a multikinase angiogenesis inhibitor with potent antitumor and antiangiogenic activity," Molecular Cancer Therapeutics, vol. 6, no. 7, pp. 2012-2021, 2007.

[30] H. I. Hurwitz, A. Dowlati, S. Saini et al., "Phase I trial of pazopanib in patients with advanced cancer," Clinical Cancer Research, vol. 15, no. 12, pp. 4220-4227, 2009.

[31] M. S. Brose, J. Smit, J. Capdevila et al., "Regional approaches to the management of patients with advanced, radioactive iodinerefractory differentiated thyroid carcinoma," Expert Review of Anticancer Therapy, vol. 12, no. 9, pp. 1137-1147, 2012.

[32] J. Capdevila, G. Argiles, V. Rodriguez-Frexinos, I. Nuñez, and J. Tabernero, "New approaches in the management of radioiodine-refractory thyroid cancer: the molecular targeted therapy era," Discovery medicine, vol. 9, no. 45, pp. 153-162, 2010.

[33] D. C. McFarland and K. J. Misiukiewicz, "Sorafenib in radioactive iodine-refractory well-differentiated metastatic thyroid cancer," OncoTargets and Therapy, vol. 7, pp. 1291-1299, 2014.

[34] S. W. Bayles, T. T. Kingdom, and G. W. Carlson, "Management of thyroid carcinoma invading the aerodigestive tract," The Laryngoscope, vol. 108, no. 9, pp. 1402-1407, 1998.

[35] T. V. McCaffrey, E. J. Bergstralh, and I. D. Hay, "Locally invasive papillary thyroid carcinoma: 1940-1990," Head and Neck, vol. 16, no. 2, pp. 165-172, 1994.

[36] J. C. McCaffrey, "Aerodigestive tract invasion by well-differentiated thyroid carcinoma: diagnosis, management, prognosis, and biology," The Laryngoscope, vol. 116, no. 1, pp. 1-11, 2006.

[37] J. M. Czaja and T. V. McCaffrey, "The surgical management of laryngotracheal invasion by well-differentiated papillary thyroid carcinoma," Archives of Otolaryngology-Head \& Neck Surgery, vol. 123, no. 5, pp. 484-490, 1997.

[38] M. Friedman, J. A. Danielzadeh, and D. D. Caldarelli, “Treatment of patients with carcinoma of the thyroid invading the airway," Archives of Otolaryngology-Head \& Neck Surgery, vol. 120, no. 12, pp. 1377-1381, 1994.

[39] M. Brauckhoff, A. MacHens, P. N. Thanh et al., "Impact of extent of resection for thyroid cancer invading the aerodigestive tract on surgical morbidity, local recurrence, and cancer-specific survival," Surgery, vol. 148, no. 6, pp. 1257-1266, 2010.

[40] H. A. Gaissert, J. Honings, H. C. Grillo et al., "Segmental laryngotracheal and tracheal resection for invasive thyroid carcinoma," The Annals of Thoracic Surgery, vol. 83, no. 6, pp. 1952-1959, 2007.

[41] T. M. McCarty, J. A. Kuhn, W. L. Williams Jr. et al., "Surgical management of thyroid cancer invading the airway," Annals of Surgical Oncology, vol. 4, no. 5, pp. 403-408, 1997.

[42] K. Tsukahara, I. Sugitani, and K. Kawabata, "Surgical management of tracheal shaving for papillary thyroid carcinoma with tracheal invasion," Acta Oto-Laryngologica, vol. 129, no. 12, pp. 1498-1502, 2009.
[43] R. J. Robbins, Q. Wan, R. K. Grewal et al., "Real-time prognosis for metastatic thyroid carcinoma based on $2-\left[{ }^{18} \mathrm{~F}\right]$ fluoro-2deoxy-D-glucose-positron emission tomography scanning," The Journal of Clinical Endocrinology \& Metabolism, vol. 91, no. 2, pp. 498-505, 2006.

[44] D. Deandreis, A. Al Ghuzlan, S. Leboulleux et al., "Do histological, immunohistochemical, and metabolic (radioiodine and fluorodeoxyglucose uptakes) patterns of metastatic thyroid cancer correlate with patient outcome?" Endocrine-Related Cancer, vol. 18, no. 1, pp. 159-169, 2011.

[45] W.-X. Qi, Y.-J. Sun, L.-N. Tang, Z. Shen, and Y. Yao, "Risk of gastrointestinal perforation in cancer patients treated with vascular endothelial growth factor receptor tyrosine kinase inhibitors: a systematic review and meta-analysis," Critical Reviews in Oncology/Hematology, vol. 89, no. 3, pp. 394-403, 2014.

[46] M. Schlumberger, M. Tahara, L. J. Wirth et al., "Lenvatinib versus placebo in radioiodine-refractory thyroid cancer," The New England Journal of Medicine, vol. 372, no. 7, pp. 621-630, 2015.

[47] Eisai Co. L. Lenvima Package Insert, 2016.

[48] D. R. Spigel, J. D. Hainsworth, D. A. Yardley et al., "Tracheoesophageal fistula formation in patients with lung cancer treated with chemoradiation and bevacizumab," Journal of Clinical Oncology, vol. 28, no. 1, pp. 43-48, 2010.

[49] B. Goodgame, N. Veeramachaneni, A. Patterson, and R. Govindan, "Tracheo-esophageal fistula with bevacizumab after mediastinal radiation," Journal of Thoracic Oncology, vol. 3, no. 9, pp. 1080-1081, 2008.

[50] E. Gore, A. Currey, and N. Choong, "Tracheoesophageal fistula associated with bevacizumab 21 months after completion of radiation therapy," Journal of Thoracic Oncology, vol. 4, no. 12, pp. 1590-1591, 2009.

[51] T. Y. Seiwert, D. J. Haraf, E. E. W. Cohen et al., "Phase I study of bevacizumab added to fluorouracil- and hydroxyurea-based concomitant chemoradiotherapy for poor-prognosis head and neck cancer," Journal of Clinical Oncology, vol. 26, no. 10, pp. 1732-1741, 2008.

[52] D. P. Blevins, R. Dadu, M. Hu et al., "Aerodigestive fistula formation as a rare side effect of antiangiogenic tyrosine kinase inhibitor therapy for thyroid cancer," Thyroid, vol. 24, no. 5, pp. 918-922, 2014. 


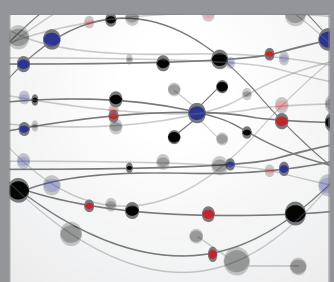

The Scientific World Journal
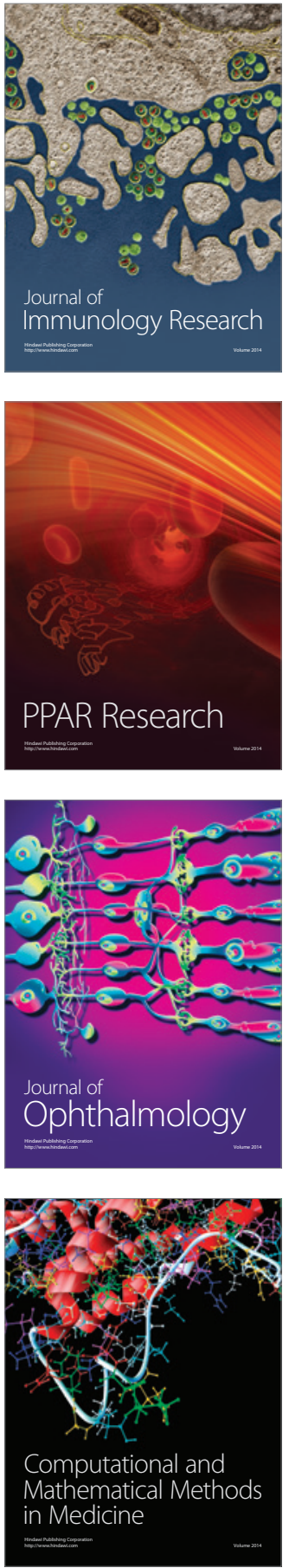

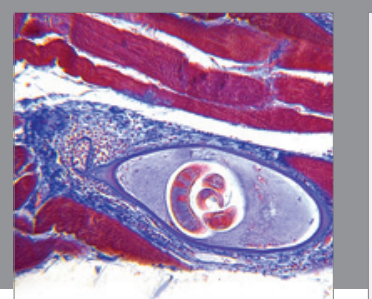

Gastroenterology Research and Practice

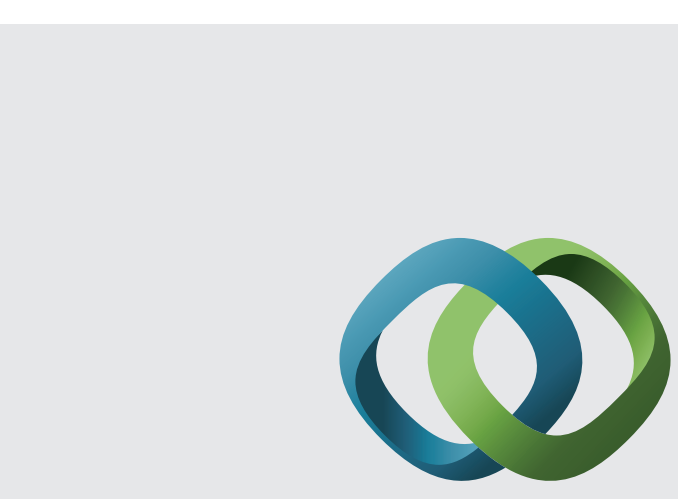

\section{Hindawi}

Submit your manuscripts at

http://www.hindawi.com
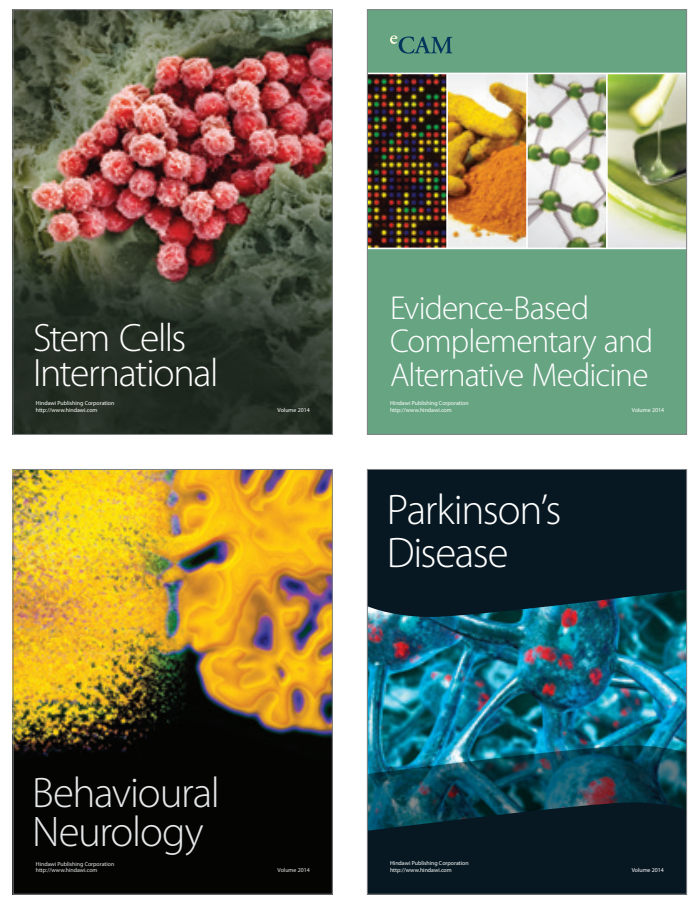
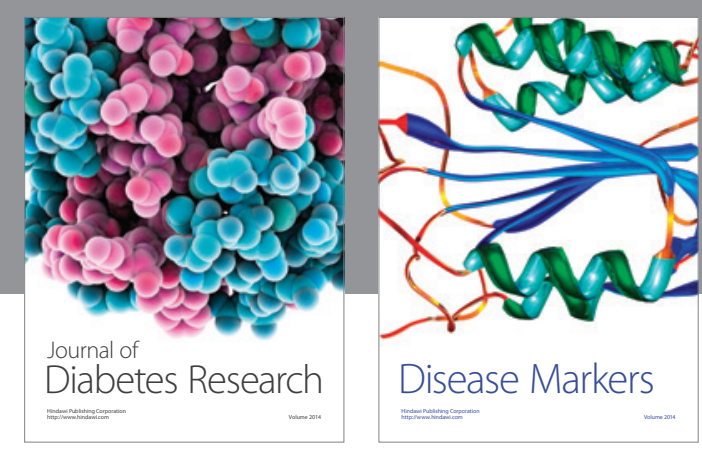

Disease Markers
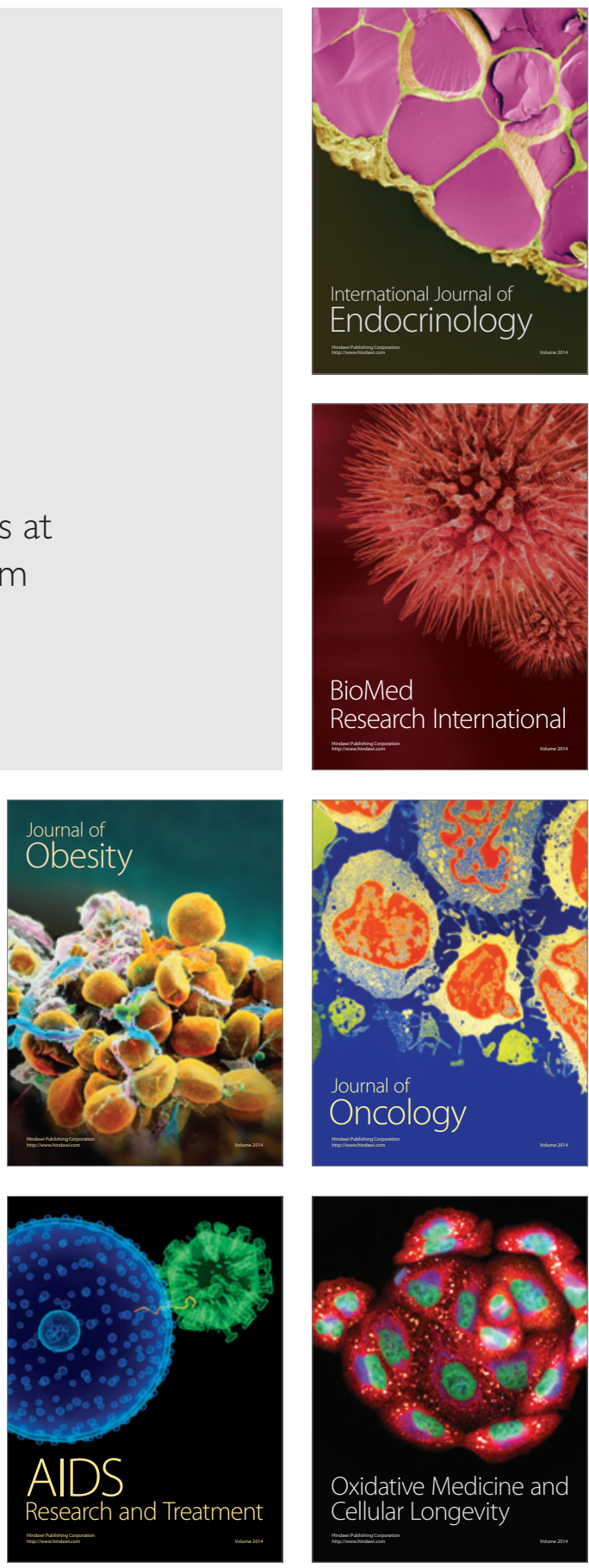